Anuario de

Derechos Humanos 2005 
Examen de los Informes Presentados por los Estados Partes de Conformidad con los Artículos 16 y 17 del Pacto*

\section{Observaciones Finales del Comité de Derechos Económicos, Sociales y Culturales. Chile}

\author{
Consejo Económico y Social
}

Comité de Derechos Económicos,

Sociales y Culturales

$33^{\circ}$ período de sesiones

8 a 26 de noviembre de 2004

E/C.12/1/Add.105

$1^{\circ}$ de diciembre de 2004

1. E I Comité de Derechos Económicos, Sociales y Culturales examinó el tercer informe periódico de Chile sobre la aplicación del Pacto Internacional de Derechos Económicos, Sociales y Culturales (véase E/1994/104/Add.26) en sus sesiones $44^{a}$ y $46^{a}$, celebradas los días 18 y 19 de noviembre de 2004 (véase E/C.12/2004/SR.44 a 46), y, en su $56^{a}$ sesión, celebrada el 26 de noviembre de 2004, aprobó las observaciones finales que figuran a continuación.

A. Introducción

2. El Comité celebra que el Estado Parte haya presentado el tercer informe periódico, que se elaboró de conformidad con las directrices del Comité. También agradece las completas respuestas presentadas por escrito a la lista de cuestiones.

3. El Comité se congratula del diálogo constructivo sostenido con la delegación de alto nivel del Estado Parte, que estuvo integrada por expertos de importantes instituciones públicas.

\section{B. Aspectos positivos}

4. El Comité observa con aprecio las mejoras de diversos indicadores sociales, como la importante disminución de la mortalidad maternoinfantil y el aumento del número de niños que asisten a la escuela primaria y secundaria, y los progresos hechos en la reducción de la pobreza.
* Un comentario acerca del Informe presentado por Chile se encuentra en la Sección Nacional de este Anuario, ver página 167.
Este documento está disponible en formato digital en www.anuariocdh.uchile.cl 
5. El Comité acoge con satisfacción la iniciativa "No hay mañana sin ayer", que contribuye a arrojar luz sobre las violaciones de derechos humanos cometidas entre el 11 de septiembre de 1973 y el 10 de marzo de 1990 y a mejorar la promoción y protección de los derechos humanos en el Estado Parte.

6. El Comité se congratula de la aprobación y ejecución de programas específicos para mejorar la situación de los grupos más pobres de la sociedad, como Chile Solidario y el Plan AUGE (Plan de Acceso Universal con Garantías Explícitas).

7. El Comité celebra las medidas adoptadas para mejorar la situación de los pueblos indígenas, entre ellas la aprobación de la Ley indígena (No 19253) de 1993, el establecimiento de la Corporación Nacional de Desarrollo Indígena (CONADI) y el Fondo de Tierras y Aguas Indígenas, y la recién anunciada Política de Nuevo Trato 2004-2010.

8. El Comité celebra la entrada en vigor, en noviembre de 2004, de la nueva Ley de matrimonio civil, que legaliza el divorcio.

9. El Comité observa complacido que en enero de 2004 se aprobó la Ley de delitos de explotación sexual comercial.

10. El Comité se congratula de la amplia información sobre la situación de la atención de salud presentada por el Estado Parte, que incluye datos desglosados por años, lo que permite al Comité evaluar el grado de realización del derecho a la salud.

C. Factores y dificultades que obstaculizan el cumplimiento del Pacto

11. El Comité observa que no hay factores o dificultades significativas que obstaculicen el cumplimiento efectivo del Pacto en el Estado Parte.

\section{Principales motivos de preocupación}

12. El Comité observa que la enmienda del artículo 5 de la Constitución efectuada en 1989 amplía la serie de derechos consagrados en el artículo 19 de la Constitución al incorporar los derechos garantizados en los tratados internacionales en que Chile es Parte. Sin embargo, al Comité le preocupa que algunos derechos económicos, sociales y culturales, como el derecho a la vivienda, no se consideren justiciables en el Estado Parte. A este respecto, el Comité observa la escasez de jurisprudencia en que los derechos enunciados en el Pacto se han invocado ante los tribunales nacionales, o en que éstos les han dado cumplimiento directamente.

13. El Comité toma nota con preocupación de la falta de reconocimiento constitucional de los pueblos indígenas en el Estado Parte y observa que estos pueblos, no obstante la existencia de diversos programas y políticas encaminados a mejorar su situación, siguen estando en 
situación de desventaja en el disfrute de los derechos garantizados por el Pacto. También lamenta que el Estado Parte no haya ratificado el Convenio No 169 (1989) sobre pueblos indígenas y tribales de la Organización Internacional del Trabajo (OIT), y que las reclamaciones por las tierras indígenas y los recursos naturales que están pendientes de resolución sigan dando lugar a discrepancias y conflictos.

14. El Comité está profundamente preocupado por la aplicación de leyes especiales, como la Ley de seguridad del Estado ( $\mathrm{N}^{\circ} 12927$ ) y la Ley antiterrorista ( $\left.N^{\circ} 18314\right)$, en el contexto de las actuales tensiones por las tierras ancestrales en las zonas mapuches.

15. Al Comité le preocupa que, a pesar de que el Estado Parte ha procurado promover la igualdad de género, los estereotipos culturales sobre el papel de ambos sexos siguen menoscabando el disfrute en pie de igualdad de los derechos económicos, sociales y culturales por hombres y mujeres.

16. El Comité observa con inquietud que la participación de las mujeres en la fuerza de trabajo sigue siendo una de las más bajas de América Latina (el 35\% en 2002). El Comité toma conocimiento a este respecto de la serie de obstáculos a la plena integración de la mujer en la fuerza de trabajo señalada por el Estado Parte en sus respuestas por escrito a la lista de cuestiones del Comité.

17. El Comité expresa preocupación por la información de que el salario mínimo aún no es suficiente para garantizar un nivel de vida digno a los trabajadores y sus familias.

18. El Comité expresa preocupación porque el artículo 381 del Código del Trabajo prevé la posibilidad de sustituir a los trabajadores en huelga. Además, le inquieta que los servicios esenciales en que se puede prohibir la huelga no estén definidos con suficiente precisión en el artículo 384.

19. Al Comité le inquieta profundamente que el régimen de pensiones privado, basado en cotizaciones individuales, no garantice una seguridad social adecuada a un gran sector de la población que no trabaja en la economía estructurada o no puede hacer contribuciones suficientes al régimen, como el amplio grupo de los trabajadores de temporada y temporales. El Comité observa que las mujeres se ven particularmente afectadas a este respecto: las "amas de casa" y alrededor del $40 \%$ de las mujeres trabajadoras no cotizan en el plan de seguridad social y por consiguiente no tienen derecho a prestaciones de vejez. Además, al Comité le inquieta que las mujeres trabajadoras tengan pensiones medias muy inferiores a las de los hombres, porque se jubilan cinco años antes.

20. El Comité está preocupado porque no se ha completado aún la reforma legislativa iniciada hace diez años para tipificar como delito el acoso sexual y sancionarlo. 
21. El Comité observa que el artículo 349 del Código de Comercio discrimina a las mujeres que no optan por el régimen matrimonial de separación de bienes.

22. Al Comité le preocupa el gran número de niños que trabajan en la industria del sexo en el Estado Parte.

23. A pesar de los grandes progresos hechos en los últimos años y de las medidas adoptadas en el marco del programa Chile Solidario, destinado a las familias que viven en la extrema pobreza, al Comité le preocupa la pobreza que existe en el Estado Parte, especialmente entre los indígenas.

24. A pesar de la construcción de muchas unidades habitacionales, al Comité le inquieta el gran número de personas que viven en asentamientos ilegales en el Estado Parte y que, por consiguiente, están expuestas a desalojos forzosos.

25. Al Comité le preocupan las consecuencias para la salud de la mujer de la prohibición legal del aborto, sin excepciones, en el Estado Parte. Aunque no hay estadísticas oficiales del número de abortos que se practican anualmente, el gran número de mujeres que se hospitalizan por complicaciones de abortos cada año (34.479 en 2001) da una indicación de la amplitud del problema.

26. Al Comité le preocupa que, no obstante los avances hechos en la lucha contra la propagación de la infección por el VIH/SIDA en el Estado Parte, esas infecciones aún van en aumento. También observa con preocupación las altas tasas de infecciones de transmisión sexual entre las mujeres jóvenes.

27. El Comité está preocupado por el alcance de la prevista ley (sobre racionalización de subsidios de incapacidad laboral y licencias médicas) por la cual se restringiría la ley actual, que permite a los padres obtener una licencia con sueldo en caso de grave enfermedad de un hijo menor de 1 año de edad.

28. Aunque tiene en cuenta los progresos realizados en la cobertura de educación, el Comité está preocupado por la calidad dispar de la educación que se imparte en las escuelas públicas y privadas, así como por las tasas de deserción relativamente altas, especialmente entre las adolescentes.

\section{E. Sugerencias y recomendaciones}

29. El Comité recomienda al Estado Parte que prosiga sus esfuerzos para dar pleno efecto al Pacto en las leyes internas, y que siga aclarando la aplicabilidad directa del Pacto en los tribunales nacionales y comunique la jurisprudencia pertinente en su próximo informe periódico. A este respecto, el Comité remite al Estado Parte a su Observación general № 9 sobre la aplicación interna del Pacto. El Estado Parte debería velar por que en la formación judicial se tenga plenamente en cuenta la exigibilidad 
de los derechos enunciados en el Pacto, y adoptar medidas para que se conozca mejor la posibilidad de invocar sus disposiciones ante los tribunales.

30. El Comité recomienda al Estado Parte que garantice la existencia de un marco jurídico e institucional eficaz para la promoción y protección de todos los derechos enunciados en el Pacto.

31. El Comité alienta al Estado Parte a que Ileve adelante sus planes de establecer una institución nacional de derechos humanos independiente, de conformidad con los Principios relativos al estatuto de las instituciones nacionales de promoción y protección de los derechos humanos (Principios de París), que figuran en el anexo de la resolución 48/134 de la Asamblea General, con el mandato de promover y proteger todos los derechos humanos, comprendidos los derechos económicos, sociales y culturales.

32. El Comité recomienda al Estado Parte que incluya el reconocimiento de sus pueblos indígenas en la Constitución, ratifique el Convenio $N^{\circ} 169$ de la OIT y siga reforzando sus iniciativas para garantizar el disfrute efectivo de los derechos económicos, sociales y culturales por los indígenas.

33. El Comité recomienda al Estado Parte que tenga plenamente en cuenta las recomendaciones formuladas por el Relator Especial sobre la situación de los derechos humanos y las libertades fundamentales de los indígenas (E/CN.4/2004/80/Add.3) acerca de la aplicación de la Política de Nuevo Trato 2004-2010, a saber, que se aumente sustancialmente el Fondo de Tierras; que se intensifiquen los esfuerzos para recuperar las tierras indígenas, especialmente en las zonas mapuches; y que se mejore la situación de los indígenas en las zonas rurales, en particular en lo que respecta a la salud y la educación.

34. El Comité recomienda al Estado Parte que no aplique leyes especiales, como la Ley de seguridad del Estado ( $\left.N^{\circ} 12927\right)$ y la Ley antiterrorista ( $\left.N^{\circ} 18314\right)$, a actos relacionados con la lucha social por la tierra y las reclamaciones legítimas de los indígenas.

35. El Comité recomienda al Estado Parte que intensifique aún más los esfuerzos para promover la igualdad de género en todas las esferas de la sociedad, entre otras cosas dotando al Servicio Nacional de la Mujer (SERNAM) del apoyo y los recursos necesarios.

36. El Comité insta al Estado Parte a que adopte medidas efectivas contra las muchas barreras que impiden la participación de la mujer en el mercado laboral. En particular, debería fomentar condiciones de empleo que respeten la vida familiar $y$ proporcionar suficientes recursos y apoyo a los programas que permiten a los progenitores conjugar la familia y el empleo, como las guarderías que tiene pensado crear el Servicio Nacional de la 
Mujer. También le recomienda que incorpore en su ordenamiento jurídico el principio de igual remuneración por trabajo de igual valor para hombres y mujeres.

37. El Comité recomienda, de conformidad con las observaciones formuladas por la Comisión de Expertos de la OIT en 2003 acerca del Convenio $N^{\circ} 111$ sobre la discriminación (empleo y ocupación), que el Estado Parte revoque explícitamente las disposiciones del derecho laboral que ya no se aplican.

38. El Comité recomienda al Estado Parte que adopte medidas con el fin de asegurar que el salario mínimo sea suficiente para que los trabajadores y sus familias lleven una vida digna, y que en su próximo informe periódico proporcione información más detallada sobre la relación entre el salario mínimo y la canasta básica de alimentos.

39. El Comité alienta al Estado Parte a que ratifique la Convención Internacional sobre la protección de los derechos de todos los trabajadores migratorios y de sus familiares.

40. El Comité alienta al Estado Parte que ratifique los Convenios $\mathrm{N}^{\circ}$ 81, 102, 117 y 118 de la OIT.

41. El Comité anima al Estado Parte a que vele por que no se restrinjan los derechos sindicales de las autoridades judiciales y los miembros de los partidos políticos establecidos en el artículo 8 del Pacto. Asimismo, lo alienta a que revise el artículo 381 del Código del Trabajo, que prevé la posibilidad de sustituir a los trabajadores en huelga, y el artículo 384, que contiene una definición demasiado poco precisa de los servicios esenciales en que la huelga está prohibida.

42. El Comité recomienda al Estado Parte que adopte medidas efectivas para que todos los trabajadores gocen de prestaciones de seguridad social adecuadas, con inclusión de medidas especiales para prestar asistencia a los grupos que actualmente no pueden hacer cotizaciones al régimen privado de seguridad social, prestando particular atención a la situación de desventaja de la mujer y del gran número de trabajadores temporales y de temporada y de trabajadores de la economía no estructurada.

43. El Comité alienta al Estado Parte a que acelere la adopción de las propuestas enmendadas a la Ley $\mathrm{N}^{\circ} 19325$ sobre la violencia intrafamiliar que están actualmente en examen.

44. El Comité recomienda al Estado Parte que acelere la aprobación del proyecto de ley que tipifica como delito el acoso sexual y lo sanciona.

45. El Comité recomienda al Estado Parte que enmiende el artículo 349 del Código de Comercio para garantizar que la mujer pueda ejercer sus actividades comerciales en igualdad de condiciones con el hombre. 
46. El Comité recomienda al Estado Parte que adopte más medidas contra el abuso sexual y la explotación sexual comercial de los niños y que disponga la debida atención de las víctimas.

47. El Comité recomienda al Estado Parte que realice estudios de la situación de los niños de la calle con vistas a formular políticas eficaces para solucionar este problema.

48. El Comité alienta al Estado Parte a que ratifique el Protocolo para prevenir, reprimir y sancionar la trata de personas, especialmente mujeres y niños, y el Protocolo contra el tráfico ilícito de migrantes por tierra, mar y aire, que complementan la Convención de las Naciones Unidas contra la Delincuencia Organizada Transnacional.

49. El Comité recomienda al Estado Parte que prosiga e intensifique sus esfuerzos para reducir la pobreza, especialmente entre los pueblos indígenas, y que integre los derechos económicos, sociales y culturales en todos sus programas de alivio de la pobreza. A este respecto, remite al Estado Parte a la declaración sobre la pobreza aprobada por el Comité el 4 de mayo de 2001. Recomienda asimismo al Estado Parte que vele por que se asignen suficientes recursos a la consecución de las metas y objetivos establecidos en el marco de los programas Chile Solidario y Chile Barrio.

50. El Comité insta al Estado Parte a que adopte medidas efectivas para promover el derecho a la vivienda, especialmente de los grupos desfavorecidos y marginados, y a que vele por que se ofrezca una protección adecuada a las personas que viven en asentamientos ilegales y pueden ser objeto de desalojos forzosos. El Comité recuerda a este respecto sus Observaciones generales $N^{\circ} 4$ (sobre el derecho a una vivienda adecuada) y $\mathrm{N}^{\circ} 7$ (sobre el derecho a una vivienda adecuada: los desalojos forzosos), y pide al Estado Parte que proporcione más información sobre el número y la naturaleza de los desalojos forzosos en su siguiente informe periódico.

51. El Comité pide al Estado Parte que en su próximo informe periódico facilite información acerca de la naturaleza y el alcance del problema de la falta de vivienda en el Estado Parte.

52. El Comité recomienda al Estado Parte que revise su legislación y despenalice el aborto cuando se trate de abortos terapéuticos y cuando el embarazo sea consecuencia de violación o incesto.

53. El Comité recomienda al Estado Parte que fortalezca las medidas encaminadas a promover los programas de educación sobre la salud sexual y reproductiva y a dar a conocer mejor los métodos anticonceptivos seguros y aumentar el acceso a ellos. Asimismo, recomienda al Estado Parte que intensifique sus esfuerzos, por ejemplo mediante campañas de información pública, para frenar la propagación de las enfermedades de transmisión sexual. 
54. El Comité recomienda al Estado Parte que refuerce las iniciativas, entre otras cosas mediante campañas de información pública, para frenar la propagación del VIH/SIDA y otras enfermedades de transmisión sexual y que en su próximo informe periódico facilite información sobre el efecto de las medidas adoptadas, incluidos los efectos de las campañas por televisión y otros medios de información, así como sobre el papel desempeñado por la sociedad civil y los grupos religiosos a este respecto.

55. El Comité recomienda al Estado Parte que revise la legislación propuesta por la que se reducirían las prestaciones del sistema de licencias médicas para los padres, con el fin de garantizar que no represente una medida retrógrada que afecte al derecho mínimo a la salud, como se expone en la Observación general № 14 del Comité.

56. El Comité recomienda al Estado Parte que vele por que la mujer en edad reproductiva no sea objeto de discriminación en el sistema de atención de salud privado.

57. El Comité pide al Estado Parte que en su próximo informe periódico proporcione puntos de referencia con respecto a los esfuerzos realizados para reducir los desechos y reciclar una mayor parte de ellos.

58. El Comité recomienda al Estado Parte que siga intensificando sus esfuerzos por mejorar la calidad de la educación en las escuelas públicas y que aborde la cuestión de la deserción, especialmente entre las adolescentes, por ejemplo prestando el apoyo adecuado a las madres adolescentes para que puedan seguir sus estudios.

59. El Comité alienta al Estado Parte a que aumente el acceso a los medicamentos genéricos haciendo uso de las cláusulas de flexibilidad que contiene el Acuerdo sobre los Aspectos de los Derechos de Propiedad Intelectual relacionados con el Comercio (Acuerdo sobre los ADPIC) de la Organización Mundial del Comercio (OMC).

60. El Comité alienta al Estado Parte a que imparta educación sobre los derechos humanos en las escuelas a todos los niveles y a que dé a conocer mejor los derechos humanos, en particular los derechos económicos, sociales y culturales, entre los funcionarios públicos, con inclusión de las fuerzas armadas, el personal encargado de hacer cumplir la ley y el poder judicial.

61. El Comité pide al Estado Parte que dé amplia difusión a sus observaciones finales en todos los niveles de la sociedad, incluidos los funcionarios públicos y el poder judicial, y que en su próximo informe periódico comunique al Comité todas las medidas adoptadas para Ilevarlas a la práctica. También alienta al Estado Parte a que siga consultando con las organizaciones no gubernamentales y otros miembros de la sociedad civil en la preparación de su cuarto informe periódico.

62. El Comité pide al Estado Parte que presente su cuarto informe periódico a más tardar el 30 de junio de 2009. 